\title{
ANTIGÜEDAD Y EDAD MEDIA ¿MAGIA, BRUJERÍA O RELIGIÓN?
}

\author{
María Verónica Sepúlveda U². \\ Facultad de Artes \\ Universidad de Chile \\ verosep2@gmail.com
}

\section{I.- INTRODUCCIÓN}

En nuestra vida siempre está presente un poco de magia, bajo los más variados aspectos, mostrándose al investigador como algo misterioso y planteando numerosas interrogantes. El estudio acerca de este tema es importante como punto de partida para realizar incursiones en muchas áreas de la cultura; asimismo, resulta revelador para explorar aquella complejidad de las relaciones entre las ocultas facetas culturales.

En la medida que el hombre necesita respuestas ante las manifestaciones del entorno, cuyo origen desconoce, le ha sido necesario atribuirlas a algo o a alguien: ¿la magia?

La intención de este trabajo es examinar el alcance de las creencias y de las prácticas mágicas desde la antigüedad hasta el medioevo cristiano.

De la herencia transmitida por la antigüedad clásica fue la concepción de la magia como una actividad que realizaban individuos especiales, que poseían cierta formación tal vez más práctica que teórica, por ejemplo en el caso de la de medicina popular, es por ello, que se tiende a confundir magia y ciencia, especialmente en lo relacionado a los poderes y efectos de la llamada magia natural. Las prácticas de estos adivinos o sanadores populares se irán reduciendo progresivamente debido al desarrollo de la medicina universitaria hacia los siglos XII y XIII.

\section{II.- DESARROLLO HISTÓRICO.}

\footnotetext{
${ }^{1}$ Publicado en VI Jornadas Interdisciplinaria. Páginas 125 - 134

${ }^{2}$ La Prof. Sepúlveda era académica en el Departamento de Teoría e Historia del Arte de la Facultad de Artes de la Universidad de Chile. En la actualidad hace clases en la Universidad Metropolitana.

Cuadernos Judaicos ISSN: 0718-8749 Volumen Aniversario 50 años 
Castiglioni divide la historia de la magia en los siguientes períodos: la antigüedad, época medieval, renacimiento y edad moderna. Seguiremos a dicho autor en la periodicidad y trataremos los dos primeros momentos.

\section{1.-PERIODO ANTIGUO.}

La magia hebrea se origina en el período que puede llamarse prehistoria, y continúa hasta el $700 \mathrm{AC}$. Se ha dicho que la religión fue creada por los profetas con un estricto sentido ético monoteísta. En la historia del pueblo de Israel, durante la época que precede a la legislación monoteísta, la magia ocupa un importante papel. El sacrificio de sangre del cual se habla repetidamente en la Biblia como una práctica esencial del culto, deriva directamente de las antiguas prácticas mágicas. Con posterioridad, la substitución de ese sacrificio humano por el de un animal se representa claramente en la narración del sacrificio de Isaac.

La prohibición de la magia, según la ley mosaica, era causada por servir a dioses extranjeros y no debido a su ineficacia. Debemos tener presente que en realidad esta fundamentación se hará válida para las posteriores prohibiciones tales como las de griegos y judíos; de romanos hacia cristianos; de cristianos hacia cualquier otro grupo considerados como herejes o paganos. El motivo inmediato de las prohibiciones y acusaciones, bien pudo ser una cuestión de meros intereses por parte de ciertos grupos o comunidades.

En la antigüedad clásica la palabra "magia" se refería en primer lugar a las artes de los magos, o de los sacerdotes zoroastricos de Persia que conocieron los griegos en el siglo V AC. Al parecer, algunos de ellos imaginaron al mundo mediterráneo. Estos magos practicaban la astrología y en general poseían conocimiento de lo oculto. Por ser magos extranjeros con capacidades exóticas que provocaban recelo, el término magia tuvo profundas y oscuras connotaciones emocionales. La magia se consideraba como algo siniestro y amenazador. Estas ideas mágicas persistieron constantemente entre las gentes que vivían en las montañas. Allí permaneció la creencia en la existencia de magos, los cuales por medio de ritos y ungüentos, tenían el poder de transformar a los hombres en animales y plantas.

Cuadernos Judaicos ISSN: 0718-8749

Volumen Aniversario 50 años 
El mago, por el hecho de que sus estudios tenían carácter abstracto, adquiría una especial importancia. Llegaba a ser un maestro, quien se había inclinado hacia la ciencia, aunque prefirió seguir siendo un práctico, un positivista, puesto que la magia implicaba la manipulación práctica de las cosas de este mundo.

La astrología se constituyó sobre las bases de la astronomía científica que se desarrolla en Mesopotamia hacia el siglo V; el horóscopo babilonio más antiguo que ha sobrevivido data del 410 AC, pero el desarrollo de la astrología científica se produjo posteriormente dentro del mundo griego.

Las obras de Aristóteles fueron importantes porque su filosofía sentó las bases intelectuales de la ciencia astrológica posterior. Consideraba que el movimiento de los cielos tenía que ver con lo que sucedía debajo de ellos, pensaba además que las estrellas y los planetas estaban compuestos por una quinta esencia superior a las cuatro restantes (tierra, aire, fuego, agua), dando paso a la justificación de la astrología en términos filosóficos.

Por su parte, fue el astrónomo egipcio Ptolomeo (52 DC) quien definió la ciencia astrológica, su obra tuvo un gran impacto en la ciencia medieval, se admitió su modelo de cosmos como un universo con la tierra en el centro, con planetas y estrellas girando a su alrededor en ciclos complejos; hasta que en el siglo XVI, cuando la teoría heliocéntrica de Copérnico fue aceptada.

A su vez, Séneca (4-65 DC) estaba convencido de la validez del movimiento de los planetas, la caída de los meteoros, el vuelo de los pájaros y la observación de rayos y relámpagos, servían como augurios de sucesos futuros. Sin embargo, para estos hombres los poderes y signos ocultos de la naturaleza no eran inherentemente mágicos; para ellos la magia era una parodia de esas cosas.

Por otro lado, Plinio habla ampliamente de la magia, que cree se origina en Persia con Zoroastro. Entre los antiguos magos, cita a Moisés, a los magos de Chipre, a los druidas, a los adivinadores y curanderos y, a los escitas devotos de la magia. Cuando Plinio habla específicamente de magia no se refiere a sus métodos, sino a los magos mostrando menosprecio hacia esos exóticos charlatanes.

Cuadernos Judaicos ISSN: 0718-8749

Volumen Aniversario 50 años 
Importante para el desarrollo de la magia fue la teoría del médico griego Galeno (131201 DC) según la cual ciertos medicamentos funcionaban de una manera prodigiosa, en virtud de su "esencia total". Trazó el camino al sugerir que una planta o animal podían tener poderes curativos prodigiosos.

En la época en que los astrólogos gozaban de reputación y fe, estaba muy difundida la creencia en las virtudes mágicas de las plantas y de los animales. Así pues, la historia de las plantas mágicas puede seguirse hasta nuestros días porque casi todas aquellas a las que los pueblos primitivos le atribuían una virtud mágica, han conservado su popularidad. La mayoría de las propiedades de las hierbas, de las piedras o de los animales podían ser explicadas en términos de su estructura física. El poder de una planta para curar ciertas dolencias, o el poder de una gema para proteger los infortunios, puede derivar no de la estructura interna del objeto, sino de una fuente externa: emanaciones procedentes de estrellas y planetas. Estos poderes se conocieron como ocultos y la magia natural era la ciencia que se ocupaba de ella. Por extensión, un poder se calificaría de oculto si estaba basado en alguna característica simbólica del objeto que poseía ese poder, y no solamente en su estructura interna.

Con relación al tratamiento de las gemas y sus poderes entran en acción los principios de simpatía y antipatía, y son los que constituyen el centro de su ciencia. Al respecto, G. Fraser se refiere a la magia simpática como aquella que funciona por una secreta empatía simbólica entre causa y efecto, aseverando que se basa en cualquier cosa que alguna vez halla estado en contacto con un objeto con el que mantiene una permanente asociación, aún después de terminado el contacto (p. 33-71).

En otros casos, el efecto del objeto mágico se basa en principios "animísticos"; es decir, está la idea de que las cosas de la naturaleza tienen espíritu o personalidades que lo habitan. Entre ellos, se consideró que la mandrágora tenía un poderoso efecto mágico al parecerse su raíz vagamente a un ser humano plantado al revés en el suelo.

La planta de la mandrágora es alabada en casi todos los recetarios de la antigüedad y de las épocas medievales, por las cualidades de sus flores, hojas y raíces, en forma de preparados para sedativos y soporíferos. Fue el remedio de más alto precio, hasta fines de la 
edad media. También es famoso como afrodisíaco, al relacionar analógicamente sus raíces con el cuerpo humano; como narcótico, y para facilitar el embarazo. Su poder ha sido confirmado por investigaciones químicas más recientes, dado que contiene substancias sedativas y estupefacientes como la atropina. Además se ha formado toda una leyenda y un ritual mágico para la cosecha de sus plantas y raíces.

Durante el siglo I en Alejandría la comunidad griega y judía vivían en constante tensión; como ejemplo citaremos que en esa época, los griegos alejandrinos acusaron en un rumor que el dios de los judíos tenía forma de burro.

Con la transferencia del centro de la civilización griega a Alejandría, la concepción mágica se hizo más simbólica y mística bajo la influencia del ambiente, donde aún vivían antiguas tradiciones procedentes de Africa central. En el período de decadencia, el culto mágico volvió a florecer y a recoger las corrientes de la magia oriental derivada de la unión de procedimientos científicos y las ideas básicas de los principios de iniciación mágicos. Alejandría, fue un punto focal para la práctica de la magia, fue lugar de desarrollo de oficios y trabajos en metal y vidrio cuyos secretos técnicos se guardaban celosamente, y donde encontramos los fundamentos de lo que más tarde se llamará alquimia.

El objeto de los estudios alquímicos era la materia con sus compuestos, lo que incitaba a entrever un dominio cercano a lo abstracto. Estaba dedicada a considerar la parte invisible de los cuerpos materiales bajo el aspecto de energía latente. La literatura sobre alquimia será leída y estudiada a fines del imperio romano y formará los cánones secretos de los iniciados en artes ocultas, y, el sentido de lo misterioso se mantendrá ya que los alquimistas usaron un lenguaje particular, iniciático y cerrado para el profano.

La importancia de la naturaleza aparece desde tiempos antiguos. Se conoce gran cantidad de remedios procedentes del reino animal, tales como los de las piedras preciosas, el jacinto, el zafiro, la esmeralda y la perla. Se atribuye una acción importante a los meteoritos y a los metales, especialmente el oro, la plata y el hierro.

En los principios de la época romana se consideraban sagrados y mágicos los bosques. Cada árbol representaba una deidad -el roble simbolizaba la robustez-y su corte era sancionado severamente por la ley. Durante un gran período de dicho imperio las personas Cuadernos Judaicos ISSN: 0718-8749 Volumen Aniversario 50 años 
con enemigos intentaron combatirlos escribiendo una maldición en algún objeto, para aumentar su eficacia se le atravesaba con la uña y se enterraba o lanzaba a un pozo; de esta manera se han recuperado amuletos con gemas. Más adelante las autoridades cristianas van a prevenir constantemente sobre los peligros de esta forma de ocultismo.

Entre los instrumentos mágicos podemos citar los amuletos, que han existido desde el comienzo de la historia. En un tiempo el término indicaba un objeto con un poder curativo; en su uso general indicaba un objeto que posee una cualidad mágica y pasiva de defender al portador de influencias maléficas. El amuleto debe llevarse sobre el cuerpo, dado que se poder deriva de su contacto con la piel. Es necesario distinguirlo de los talismanes, que ejercen una influencia mágica activa, ya que puede proporcionar fortuna o éxito a quien lo lleva. Se piensa que los talismanes y amuletos forman con el individuo un nexo indivisible. Se distinguen los fetiches que tienen una fuerza especial provocada por el mago, quien los impregna de ese poder $\mathrm{y}$, para conservarlo, se requiere de muchas prácticas y procedimientos, sin los cuales pierde su poder. Sin embargo, el poder atribuido a los factores mágicos, sean inherentes al objeto mismo o transmitidos de otros objetos, personas o animales, solo en pocos casos se conectan con poderes reales terapéuticos.

Durante los siglos IV y V el mundo romano intelectual no era totalmente cristiano. Por ejemplo, algunos autores neoplatónicos como Marciano Capella se interesaba en las interpretaciones filosóficas de la mitología y, Macrobio creía en los poderes ocultos de los números, en el significado profético de los sueños y en las propiedades ocultas de la naturaleza.

Isidoro de Sevilla (560-636 DC), relacionó la geomancia, la hidromancia, la aeromancia y la piromancia (adivinación por la tierra, el agua, el aire y el fuego) bajo el epígrafe de "magia". Después de catalogar ésta y otras formas de adivinación, incluyó los encantamientos y conjuros (utilización mágica de las palabras) los vendajes y otros fenómenos.

La creencia en la adivinación para el beneficio de los individuos existe sin interrupción a través de los siglos. La adivinación, al igual que la magia, de la que es un aspecto esencial, aparece en todas las épocas y está ligada a los orígenes de la sociedad. Constituye 
una parte importante en la vida de todas las sociedades primitivas. El deseo de un conocimiento de lo oculto se origina de la comprobación de la insuficiencia de los sentidos del hombre. A las causas de los hechos visibles que no puede explicarse, les atribuye su origen a poderes maravillosos. Al respecto Castiglioni señala:

"Este fenómeno se presenta en las sociedades que están atravesando un período de depresión, así como en las personas enfermas o convalecientes de una grave enfermedad. Sienten la necesidad de reafirmar su confianza en el futuro y protegerse del peligro" (p. 66).

El mismo autor considera a la medicina adivinatoria como parte esencial de la medicina primitiva.

Aunque los métodos de la adivinación son muchos y muy variados, según las épocas y el medio en que se produjeron, no debemos olvidar que la parte más importante de la adivinación consiste en producir el hechizo, es decir, la creación de un estado de ánimo especial en el que ciertas facultades pueden actuar, aunque la acción mágica sólo puede producirse cuando existe una perfecta relación y cooperación de las fuerzas dentro y fuera del grupo, y cuando se establece la relación estrecha con los factores que determinan la vida de ese grupo. Con relación a esto Castiglioni señala:

"En la sugestión colectiva lo notable es que en la masa, el individuo pierde su personalidad consciente y predomina la tendencia a la inmediata realización de la idea sugerida. El individuo perteneciente a una masa posee una sensación de poder e irresponsabilidad que aumenta su fuerza. El contagio es un fenómeno de fácil constatación - semejante a as condiciones hipnóticas-, hechiza a las masas hasta lograr que los individuos aislados pierdan sus facultades críticas y la comprensión de sus intereses particulares" (p. 111).

Desde sus comienzos la adivinación jugó un papel importante en Roma, estaba legalizada desde un principio y constituía una función del Estado. Era particularmente importante la interpretación del vuelo de los pájaros, originariamente una creencia etrusca. La concepción mitológica de los etruscos se personifica en la idea del "genius" que acompañaba a cada individuo y regía se estrella natal. Aunque el culto de los etruscos 
estaba centrado en una magia demoníaca, en la que "tenían una parte importante los actos sexuales espantosos y obscenos" (Castiglioni, p. 186). Una de las epístolas de Horacio revela que los bajorrelieves etruscos eran muy solicitados por los coleccionistas de arte erótico. Desde la cultura etrusca en adelante, el augurio o presagio adquirió las características de una práctica mágica perfectamente sistematizada y éste íntimamente ligado con la adivinación, apareciendo como signos premonitorios mediante los cuales se cree poder prever los resultados de una acción, sean estos favorables o desfavorables. En las antiguas civilizaciones, la interpretación de los presagios como una parte de la magia, se consideraba como una función sacerdotal, como una interpretación de la voluntad de los dioses.

Resumiendo, vemos que la magia del mundo latino, la griega y la oriental y más tarde etrusca e itálica, ejercen una profunda influencia en la evolución mágica de Roma. En época greco-romana se transformó en un factor político y social, sirviendo a los propósitos del Estado bajo el Imperio, recogiendo las ideas y creencias de los pueblos vecinos. La concepción mágica recobra su influencia a la caída del Imperio, cuando el poder y las leyes de Roma y del pueblo buscan el consuelo de las cosas misteriosas y desconocidas.

Con respecto a ello, cuando el antropólogo español Julio Caro Baroja se refiere a la magia, señala: "es la respuesta peculiar que da el hombre a un grupo de hechos concretos", asegurando además, que si bien existía en la antigüedad no se constituía en un sistema científico.

\section{2.- EDAD MEDIA}

Las ideas sobre la magia que florecieron en la Europa medieval procedieron de varias fuentes. La herencia de la cultura clásica del mediterráneo se mezcla con las de los pueblos germanos y celta del norte de Europa. Más adelante los cristianos tomaron nociones sobre la magia de los judíos y de los musulmanes. El estudio de la magia aparece, pues, como un camino hacia la comprensión de cómo diversas culturas se relacionan unas con otras. 
La cultura clásica del antiguo mundo grecorromano fue relevante para la magia medieval, los escritos de griegos, egipcios y romanos sobre magia se conservaron y tuvieron profunda importancia en la cultura del medioevo. Los hombres medievales heredaron una rica colección de escritos sobre el tema, el cómo los utilizaron dependió de la interpretación que se les diera. Así como la cultura clásica del antiguo mundo grecorromano fue una fuente importante para la magia de este momento, otro fue la cultura tradicional de los pueblos germanos y celtas llegados a la Europa cristiana, que finalmente se convirtieron al cristianismo debido al esfuerzo realizado por los misioneros y como proceso final de asimilación. Dicho proceso duró aproximadamente desde el siglo $\mathrm{V}$ al $\mathrm{X}$, fechas sólo aproximadas, puesto que los cronistas tomaron el año del bautismo de un monarca como la fecha oficial de la conversión de todo reino. De hecho la conversión rural pudo haber durado mucho más tiempo. Una vez bautizado el monarca, los lugares de culto cristianos fueron desplazados a los templos paganos. La adaptación de ciertos elementos culturales fue habitual -por ejemplo- los monjes que viajaban como misioneros encontraban encantamientos mágicos con nombres de dioses paganos, que más tarde se asimilaron a nombres cristianos. Debemos recordar que fue difícil erradicar los elementos paganos de los sistemas de creencias de muchos grupos produciéndose, en ciertos casos, un sincretismo de ideas.

En la tradición de los pueblos germanos paganos, por ejemplo en las Sagas nórdicas, aparecen los magos como personajes siniestros e impopulares, a veces relacionados implícitamente con el paganismo, y dedicados a cometer acciones horribles, por lo cual todo el grupo los condenaba a ser ejecutados o a ser desterrados. Dichos magos se presentan con poderes psíquicos especiales. Se cree que al estar dormidos o en trance pueden transformarse en animales para atacar a sus enemigos. Las antedichas sagas tratan más bien de seres humanos, mientras que las Eddas que preservan la mitología escandinava, son la fuente principal para el conocimiento de los dioses, aunque también se refieren a la magia. Como lugar común establecen que, para cualquier mago -sea divino o humano- la magia está estrechamente relacionada con la escritura. 
La literatura celta, por su parte, también contiene temas mágicos, generalmente más cercanos a las Eddas que a las Sagas. Debemos puntualizar que la literatura celta conocida nos ha llegado mayoritariamente en redacciones de la Baja Edad Media (siglos XII y XIII) algo mediatizadas por parte del cristianismo. Por ejemplo, la relación entre los humanos y las hadas es un motivo importante en la tradición irlandesa. Con frecuencia, las hadas son representadas como demonios por la cristiandad medieval, pero para ellos estas están aliadas con la fuerza del bien y de la fe y contra los druidas paganos. Vemos pues, sobre la base de este simple ejemplo que los cristianos identificaban a los dioses tradicionales de estas culturas como demonios, y cualquiera forma de magia al servicio de estos dioses fue considerada como magia diabólica. Recordemos que los primeros autores cristianos usaron el término "diabólico" como acepción de algo misterioso y oculto porque tenía la ayuda de sus dioses. Pero los dioses de los magos no eran los dioses reales, y desde el punto de vista cristiano eran demonios. Entonces, la taumaturgia del paganismo de cualquier cultura fue desenmascarada como magia diabólica. Fueron los demonios los que habían instituido las artes mágicas y ellos quienes las enseñaron a los practicantes humanos; y eran los demonios en realidad quienes llevaban a cabo los deseos de los magos. Del mismo modo, la adivinación o predicción del futuro sólo fue posible con la ayuda de los demonios.

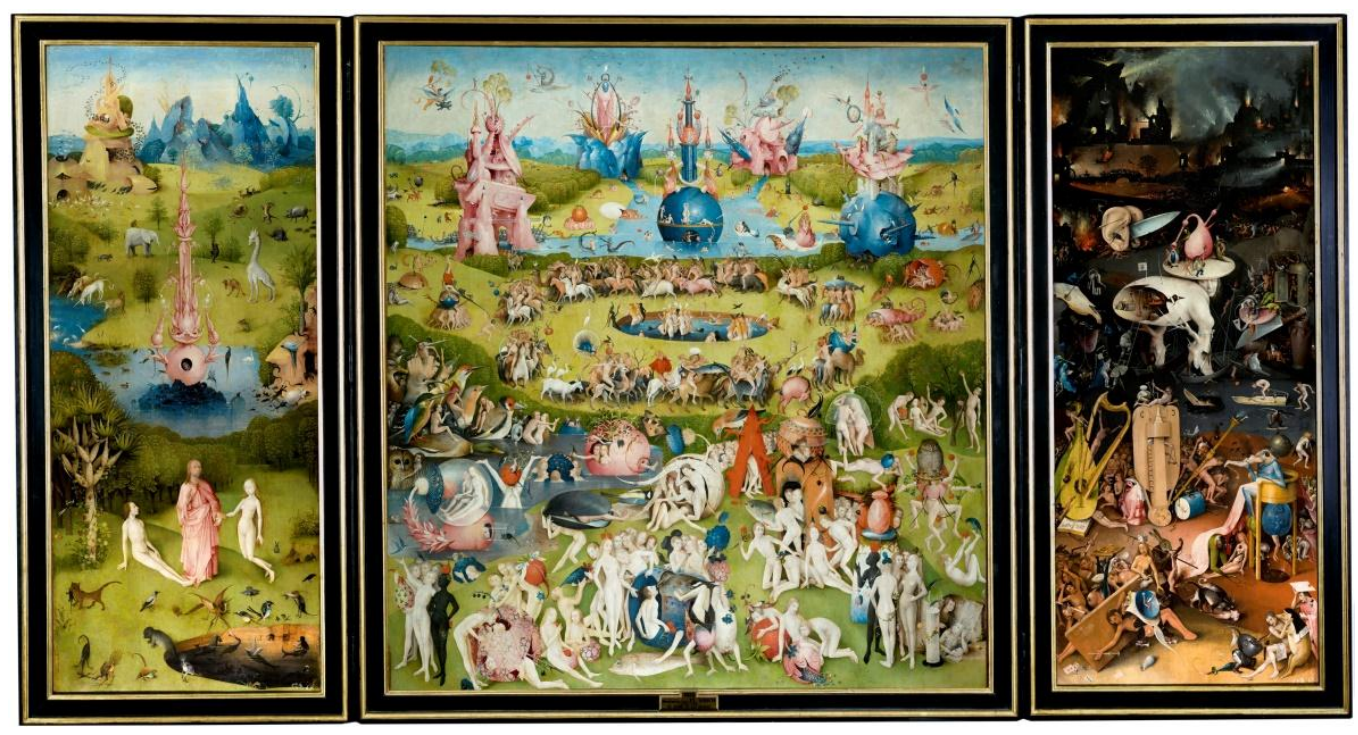

Foto de Pintura

Cuadernos Judaicos ISSN: 0718-8749

Volumen Aniversario 50 años 
“. Original del Museo de El Prado, Madrid. Imagen obtenida de la web: el Copyright:Museo Nacional del Prado

La diferenciación que hace R. Kieckhefer entre magia diabólica y magia natural, aseverando que "la magia diabólica o nigromancia invoca a los espíritus demoníacos y reposa en una red de creencias y prácticas religiosas; mientras que la magia natural explota los poderes ocultos de la naturaleza" (p. 17) tiene relación con esta visión del cristianismo. Por otra parte, para muchos autores de la Europa medieval cualquier tipo de magia era, por definición, diabólica, recalcando que no todo el mundo estuvo de acuerdo en que existía la magia natural, diferenciada de la demoníaca.

La herencia clásica acerca de los magos como individuos especiales, sigue siendo un término negativo aunque, como refiere Castiglioni, al observar quienes practicaban algún tipo de magia en la cultura medieval es difícil establecer un arquetipo ya que se involucran en la acción mágica diferentes clases de personas, tales como monjes, párrocos, médicos, barberos, sanadores populares y adivinos. Los monjes y sacerdotes que practicaron la magia, fueron quienes dejaron más testimonios escritos sobre estos conocimientos que rescataban tanto de los laicos como de los autores clásicos a los que tenían acceso en las bibliotecas de sus mismos monasterios, donde día a día se dedicaban a copiar los manuscritos.

No debemos olvidar que las nociones populares de la magia fueron adoptadas, interpretadas y definidas por "intelectuales" y por quienes tuvieron una formación filosófica o teológica. Dentro de la sociedad medieval todos aquellos que se preocuparon del estudio de la cultura, procedían del pequeño grupo de la población que sabía escribir. Los "intelectuales", tuvieron la ventaja de formular teorías y definiciones que han llegado hasta la actualidad. El resto de la sociedad también tuvo sus formas de concebir el mundo, pero sus puntos de vista son más difíciles de construir. La mentalidad popular y la erudita en ciertos casos fueron parecidas, pero en otros muy diferentes. La gente común hablaba de encantamientos, bendiciones, conjuros o curas, sin considerarlos específicamente mágicos. Solamente la elite teológica e intelectual se preocupó por esas cuestiones de definición. 
Hasta el siglo XII, si se le preguntaba a un teólogo qué era la magia, lo más probable es que respondiera que fueron los demonios quienes la empezaron y que estos mismos estaban siempre implicados en su práctica. En todo caso, al comparar ambas mentalidades notamos que en la historia de la magia confluyen -por un lado- la explotación de las fuerzas naturales junto a la invocación de los poderes de ciertos seres benéficos o maléficos, según de que óptica se miren.

Hasta el siglo XII las categorías establecidas para "magia" por Isidoro de Sevilla se mantuvieron en el uso común. Encontramos que durante el siglo XIII el teólogo Alejandro de Hales (1185-1245 DC) utilizó el término "adivinación” para distinguir varios tipos de artes ocultas que incluían a la brujería y al ilusionismo. Esto es posible de constatar puesto que escritores de la época concibieron a la magia y a la adivinación como actividades estrechamente relacionadas. No hay duda de que, la idea religiosa en sus comienzos se apoya en la concepción mágica. Tal es así que, numerosos autores consideran a la magia como la primera aplicación del concepto de causalidad ligado íntimamente con los comienzos de la religión. Sabemos, que en un principio, lo religioso acepta el simbolismo místico de la magia, adoptando en parte sus ritos y sus prácticas, y empleando su procedimiento fundamental, esto es, la preparación del ambiente por medio de la sugestión, a causa de ello las culturas del norte de Europa, al igual que las del imperio romano, relacionaron -sin hacer diferencias- la magia con la religión. Sin embargo, muy pronto la idea religiosa se alejará esencialmente de la magia para adquirir -en las concepciones monoteístas- un predominio absoluto. La religión pagana constituye un tipo de adoración al demonio, y por ende a la magia se la relaciona con éste. Ocurre entonces que, se condenan todas aquellas prácticas y las creencias consideradas paganas.

Con la aceptación de la existencia de los demonios y a causa de la oposición esencial entre la idea mágica y la religiosa que se va formando con la evolución de la idea demoníaca, se inicia la decadencia de la magia. Asimismo con el individualismo renacentista, la aparición de la crítica histórica, la iniciación de la ciencia experimental y el triunfo de la razón sobre el instinto, llevan a la relegación de muchas de las prácticas y creencias mágicas. 


\section{III.- CONCLUSION.}

En la mayoría de las culturas la magia es un punto de unión donde la religión converge con la ciencia teniendo múltiples puntos de contacto. Además es un área donde las creencias populares se mezclan con las de las clases educadas o eruditas, a su vez representa una intersección donde las convenciones de la ficción se encuentran con las realidades de la vida diaria.

$\mathrm{Al}$ respecto señala Castiglioni que:

"toda concepción humana posee una base en la realidad y deriva de una intuición, o de las conclusiones correctas o erróneas basadas en las experiencias de hechos actuales, es necesario admitir que la adivinación, que es el conocimiento de las cosas ocultas en el futuro, es tan vieja como el razonamiento humano y debe tener un principio de verdad" (p. 62).

Aunque es difícil precisar el alcance y las fronteras de la magia debido al sentido polisémico que se le ha dado en los diversos momentos, y por las distintas culturas, podemos resumir la historia de la magia medieval haciendo notar que en el ámbito de la cultura popular se tendía a concebirla como algo natural, mientras que entre los intelectuales se dieron diferencias en las líneas de pensamiento. En los primeros siglos del cristianismo existía el supuesto de que cualquier tipo de magia tenía alguna dependencia de los demonios y, posteriormente hacia el siglo XII, otros eruditos influidos por los aportes a la medicina hecho por los árabes, concebían que la mayor parte de la magia era natural, constituyendo una rama de la ciencia. Se llega a la Baja Edad Media con la idea de que la acción mágica aunque pretendiera ser una práctica inocente, comportaba la invocación explícita de los demonios.

Con relación a la intención de la acción mágica, Kieckhefer dice:

"En el siglo XVI en debates religiosos -y aceptada también en escritos antropológicos de fines del siglo XIX y principios del XX- se define magia por la intención de una acción más que por el poder al que se invoca.

Cuadernos Judaicos ISSN: 0718-8749

Volumen Aniversario 50 años 
Según esta definición, la característica principal de la religión es que suplica a Dios o a los Dioses, mientras que la característica de la magia es que obliga a seres o fuerzas espirituales. Por ello se puede decir que la religión trata a los dioses como seres libres, y la magia intenta manipular a los espíritus. De esta perspectiva, la frontera entre magia y religión se hace dificil de precisar." (p. 22-24).

\section{BIBLIOGRAFIA}

Caro Baroja, Julio Las brujas y su mundo.Alianza Editorial, Madrid, 1992.

Caro Baroja, Julio El Señor Inquisidor.Alianza Editorial, Madrid, 1994.

Castiglioni, Arturo Encantamiento y Magia. F.C.E., México, 1993.

Cohn, Norman Los demonios familiares de Europa. Alianza edit., Madrid, 1987.

Frazer, J. G. La Rama dorada. Magia y Religión. F.C.E., México, 1956.

Kieckhefer, Richard La magia en la Edad Media. Ed. Crítica, Barcelona, 1992.

Piobb, P. V. Formulario de Alta Magia. Ed. Gráfica EMA, España, 1980.

Vauchez, André La espiritualidad del occidente medieval. Ediciones Cátedra, Madrid, 1985. 